\title{
A triagem de materiais recicláveis e as variabilidades inerentes ao processo: estudo de caso em uma cooperativa
}

\author{
The sorting of recyclable waste and the variables inherent \\ to the process: a case study in a cooperative
}

Renato Luvizoto Rodrigues de Souza ${ }^{1}$

Andréa Regina Martins Fontes ${ }^{1}$

Silvana Salomão ${ }^{2}$

${ }^{1}$ Programa de PósGraduação em Engenharia de Produção de Sorocaba, Universidade Federal de São Carlos. Rod. João Leme dos Santos Km 110, Itinga. 18.052-780 Sorocaba São

Paulo Brasil.

rluvizoto@gmail.com

${ }^{2}$ Engenharia de Produção,

Universidade de Franca.

\begin{abstract}
Informal labor with recyclable materials is marked by social exclusion and discrimination, besides this activity being conducted in unsanitary conditions. The literature suggests that the problems associated with the sorting of recyclable waste are associated with lack of structure, contact with the "garbage", lack of government support, lack of training, lack of safety equipment, among others. The scope of this paper is to describe the process of sorting recyclable waste in a cooperative in França in the state of São Paulo. The specific objective was to identify the variables inherent to the process and investigate how workers adjust their work schedules to deal with these variables. The research method used is the case study with an operationalized ergonomic approach at some stages of the ergonomic analysis of work. Exploratory visits, indirect observations and semi-structured interviews were conducted. The results showed that the variables inherent to the process require that workers perform timely management sessions, which can be either collective or individual, though this invariably results in overload in the workplace, either by speeding up the work output or by demanding the increased concentration of those involved.
\end{abstract}

Key words Sorting, Variables, Cooperative, Complexity, Recyclable waste
Resumo O trabalho informal com materiais recicláveis é marcado por desvalorização e exclusão social, além desta atividade ser realizada em condições insalubres. A literatura aponta que os problemas associados à triagem de materiais recicláveis estão relacionados à falta de estrutura, ao contato com o "lixo", à falta de apoio do poder público, à falta de treinamentos, à falta equipamentos de segurança, entre outros. O objetivo geral deste artigo foi descrever o processo de triagem de materiais recicláveis na cooperativa de Franca, SP. O objetivo especifico foi identificar as variabilidades inerentes ao processo e investigar como o trabalhador molda seu trabalho para dar conta destas variabilidades. O método de pesquisa é o estudo de caso com abordagem ergonômica operacionalizada por algumas etapas da análise ergonômica do trabalho. Foram feitas visitas exploratórias, observações indiretas e entrevistas semiestruturadas. Os resultados demonstraram que as variabilidades inerentes ao processo solicitam dos cooperados uma gestão momentânea que pode ser realizada de forma coletiva ou individual, mas que quase sempre causa sobrecarga no trabalho, seja acelerando-o ou aumentando a concentração. Palavras-chave Triagem, Variabilidade, Cooperativa, Complexidade, Recicláveis 


\section{Introdução}

Localizadas na interface entre o consumo da sociedade e a indústria de reciclagem, as cooperativas são responsáveis, em alguns casos pela coleta e triagem, em outros somente pela triagem dos materiais recicláveis. Desta forma, teoricamente, o produto proveniente do processo de triagem abastece as indústrias de reciclagens e estas os transformam em bens de consumo ou matérias primas para indústrias afins.

Desta forma, os atores envolvidos na cadeia de reciclagem podem ser apontados de forma genérica na Figura 1.

A Figura 1 demonstra as relações da cadeia de reciclagem de forma genérica, ressalta-se que em alguns casos as próprias cooperativas realizam a coleta seletiva. O objetivo deste estudo é descrever o processo de triagem de materiais recicláveis em uma cooperativa visando identificar as variabilidades inerentes ao processo. A unidade de análise é a cooperativa de materiais recicláveis de Franca e Região, Cooperfran.

Foi realizado um estudo de caso único com abordagem pautada na análise ergonômica do trabalho. $\mathrm{O}$ estudo contou com observações diretas, indiretas, entrevistas e filmagens.

\section{Trabalho informal com o lixo e a saúde coletiva}

Há diversas formas de o trabalho se organizar e grandes discussões acerca do significado do trabalho, variando nas esferas do tempo e geográficas. Aqui consideraremos que o trabalho é o grande cerne que define o sujeito frente à sociedade, deixando em segundo plano as esferas políticas ou familiares ${ }^{1,2}$.

Desta forma, podemos colocar que o próprio termo "trabalho informal" já coloca o trabalhador em uma posição de marginalidade frente à sociedade, visto que este termo remete à ausência de formalidade, em um grau mais extremo à ilegalidade. Entendendo que todo o contingente de situações que afetam a saúde dos trabalhadores, formais ou informais, podem ser consideradas como uma forma de violência, em seus diversos sentidos, Gomez e Thedim-Costa ${ }^{3}$, concluem que são esses trabalhadores, excluídos e em segmentos mais vulneráreis da informalidade, os mais afetados pela atividade laboral.

Nesse sentido, fazemos aqui um recorte e aprofundamos no trabalho informal com o lixo e seus impactos para a saúde do trabalhador. Ressalta-se que estes trabalhadores além de rea-

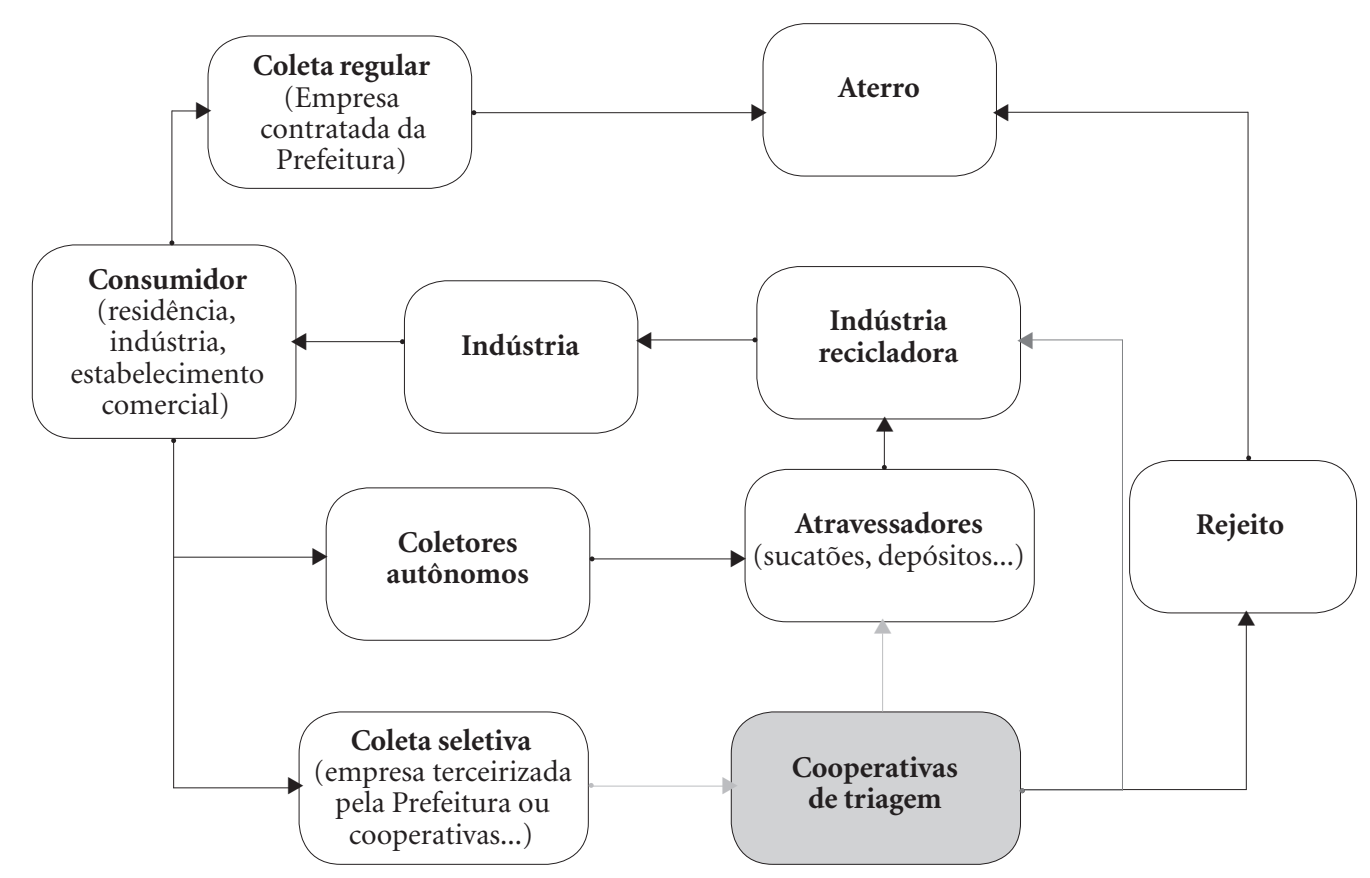

Figura 1. Descrição da seleção dos estudos. 
lizarem a sua atividade sob todas as imperfeições relatadas, ainda fazem jornadas de trabalho além do que é estipulado e ganham na maioria dos casos menos do que o salário mínimo brasilei$\mathrm{ro}^{4}$. Além disso, aponta-se que os trabalhadores da gestão dos resíduos sólidos têm 5,6 e 1,5 mais probabilidades de sofrer uma lesão no local de trabalho e contrair doenças relacionadas com os resíduos, respectivamente, do que o restante dos trabalhadores ${ }^{5,6}$.

Desta forma, concordamos com Sisinno e Oliveira $^{7}$ que os resíduos sólidos urbanos extrapolam a dimensão ambiental e devem ser tratados também como uma questão de saúde pública. Assim, para avançarmos nos estudos sobre saúde coletiva, precisamos superar paradigmas associados à departamentalização das pesquisas e encararmos estes estudos a partir de uma perspectiva interdisciplinar ${ }^{8}$.

\section{Variabilidades inerentes ao trabalho com o lixo}

A noção de variabilidade para a ergonomia está relacionada ao duplo contexto (externo e interno) em que o sujeito realiza seu trabalho - sua atividade - visando atingir os resultados propostos. No contexto interno, apontam-se os fatores inerentes ao sujeito; sua competência, seus limites físicos, suas motivações, sua capacidade, experiência, etc., no contexto externo, apontamos a organização do trabalho, abrangendo matérias primas, processos, equipamentos, processos decisórios, ritmo de trabalho, entre outros ${ }^{1,9,10}$. As variabilidades do trabalho informal com reciclagem são descritos no Quadro 1.

Nesse sentido, estas variabilidades impactam diretamente sobre a atividade dos cooperados na triagem de materiais recicláveis. A forma como o sujeito molda seu trabalho para dar conta destas variabilidades está associada à margem de manobra disponível e esta ao modo ou modos operatórios para dar conta da atividade. Portanto, Vida ${ }^{20}$ afirma que o modo operatório se constrói a partir do trabalho prescrito, o trabalhador ao desenvolver sua atividade, o constrói e desconstrói a todo momento, buscando adequar o modo operatório de acordo com as demandas dos equipamentos, matérias primas, normas sociais, etc. Desta forma, o modo operatório é o resultado da regulação feita pelo trabalhador para diminuir a lacuna entre o que lhe é solicitado (tarefa), com o que faze-lo (meios de trabalho) e como fazê-lo $o^{20}$. Conforme Oliveira ${ }^{16}$, devido à grande variedade de materiais para serem triados, os cooperados desenvolvem diferentes estratégias e modos operatórios para dar conta da atividade.

Guerin et al. ${ }^{10}$, utilizam inclusive o conceito de margem de manobra para definir carga de trabalho. Os autores colocam que é justamente quando a margem de manobra não é possível que o trabalhador é submetido a uma carga ou sobrecarga de trabalho. Desta forma, concluímos que quando o trabalhador não pode elaborar seus modos operatórios frente à tarefa, ele poderá dar conta desta, porém em detrimento da sua saúde.

\section{Triagem de materiais recicláveis em cooperativas: uma atividade complexa?}

Sabemos que a atividade de triagem em cooperativas está inserida em um sistema complexo, devido inicialmente aos seus paradoxos: como uma organização que visa a democratização da economia em um mercado capitalista ${ }^{21}$, o sócio gestor que também é trabalhador e tem que

Quadro 1. Variabilidades trabalho informal com reciclagem.

\begin{tabular}{|c|c|c|}
\hline \multicolumn{2}{|c|}{ Variabilidades } & Descrição \\
\hline \multirow{3}{*}{ Matéria Prima } & Tipos de objetos & $\begin{array}{l}\text { Produtos com restos químicos misturados aos materiais recicláveis; } \\
\text { lixo hospitalar, lixo orgânico, animais vivos e mortos (ratos, } \\
\text { cachorros, etc.), objetos perfuro cortantes e fezes }{ }^{11-18} \text {. }\end{array}$ \\
\hline & Estado do material & Contaminado, molhado, sujo e mau cheiroso ${ }^{13,16,19}$. \\
\hline & Fluxo dos materiais & Oscilação na quantidade de materiais para triagem ${ }^{16,19}$. \\
\hline Equipamentos & Maquinários & Oscilações no funcionamento dos maquinários ${ }^{19}$. \\
\hline Sujeitos & Competência & Diferentes ritmos de trabalho ${ }^{13,16,19}$. \\
\hline
\end{tabular}

Fonte: autor 
desempenhar as duas funções que podem ir de encontro uma a outra; e a própria semântica positiva e negativa do lixo, entre outros ${ }^{22}$. Porém, poder-se-ia afirmar que em organizações com sistemas complexos a atividade também será complexa?

Resgatamos então, Vasconcelos et al. ${ }^{23}$ :

Como há diferença entre sistema complexo e tarefa complexa, deve-se lembrar que a consideração de uma tarefa como complexa dependerá da representação que o trabalhador tem de sua tarefa e que a complexidade de um sistema tem relação com a variabilidade das situações, com as incertezas advindas desta variabilidade ${ }^{23}$.

De fato, muitos sistemas podem ser compostos de interações sociais e técnicas complexas, porém a complexidade objetiva de um sistema só pode ser definida por uma dada representação de um sistema e não pelo próprio sistema ${ }^{24}$, esta representação ou modelo, assim denominado por Leplat ${ }^{25}$, depende diretamente do agente inserido nesse sistema e do desenvolvimento de suas tarefas. Desta forma, uma tarefa poderá ser muito complexa para um operador e muito menos para outro, inclusive poderá existir variações na complexidade ao longo do tempo ${ }^{25}$. Conclui-se que um sistema complexo pressupõe, mas não garante uma tarefa complexa, em contrapartida sistemas considerados simples podem rebater em tarefas complexas ${ }^{23}$.

Assim, o objetivo geral deste artigo foi descrever a triagem de materiais recicláveis em cooperativas. O objetivo específico foi identificar as variabilidades inerentes ao processo e verificar como os trabalhadores fazem sua gestão.

\section{Método}

A pesquisa foi qualitativa, pois necessitou enfatizar as representações do indivíduo em determinado contexto ${ }^{26}$. Classificamos a pesquisa como descritiva/exploratória, visto que pretende-se descrever o processo de triagem e analisar os impactos das variabilidades sobre a atividade de triagem e consequentemente sobre a saúde do cooperado ${ }^{27}$.

Nesse sentido, o método de pesquisa convergiu para o estudo de caso, pois além dos pressupostos elencados no paragrafo anterior, destacase também: a contemporaneidade do fenômeno estudado; o fato de não ser exigido o controle sobre os eventos estudados; além de o estudo de caso ser o método mais utilizado em estudos com empreendimentos solidários ${ }^{19}$. O estudo de caso é definido como um método empírico que investiga determinado caso dentro de um contexto da vida real por meio de avaliações ${ }^{28,29}$.

O objeto de estudo foi a triagem de materiais recicláveis em cooperativas. O processo de triagem foi escolhido, pois é nesta etapa em que se confrontam todas as variabilidades inerentes aos materiais recicláveis e consequentemente solicita do cooperado intenso trabalho físico, muita atenção e conhecimento sobre a propriedade dos materiais ${ }^{11}$, além da triagem representar o principal gargalo da cadeia de reciclagem ${ }^{30}$. A unidade de análise deste estudo de caso foi a cooperativa de materiais recicláveis de Franca (SP) e região, Coopefran.

A coleta dos dados foi realizada no mês de novembro de 2013 e contou com uma abordagem pautada na análise ergonômica do trabalho (AET), utilizada também para a análise dos da$\operatorname{dos}^{10,20,31}$. No Quadro 2 são descritos as etapas de pesquisa de campos e procedimentos de ação utilizados na pesquisa.

\section{Resultados}

Os resultados estão embasados nos procedimentos apresentados no item de método e utilizam fundamentalmente as entrevistas com a diretoria da cooperativa e com os cooperados do setor de triagem, as análises advindas da AET e o referencial teórico.

\section{Percepção de desconforto e alta rotatividade}

Utilizando o meio de levantamento de queixas de dores de Corlett e Bishop ${ }^{32}$, constatou-se que entre os cooperados as queixas estão distribuídas conforme o Gráfico 1. Nota-se que as partes alta e baixa da coluna foram as regiões mais apontadas e que a quantidade de queixas de dores insuportáveis são mais da metade nos dois casos. A tarefa de triagem é realizada em pé e notou-se que sempre que os cooperados tinham algum tempo livre, entre a troca dos bags ou alguma parada da esteira eles procuravam sentar-se. Os ombros esquerdo e direito também receberam queixas com status insuportáveis. Estas constatações corroboram com outros estudos que evidenciaram que o trabalho com materiais recicláveis implica em dores nas costas, pernas, ombros e braços ${ }^{15,33-35}$. Vale destacar que foi solicitado que os cooperados apontassem somente as dores que eles associavam com o trabalho. 
Quadro 2. Estratégia de coleta e análise dos dados.

\begin{tabular}{|c|c|}
\hline Coleta de dados & Procedimentos de ação \\
\hline Revisão teórica & $\begin{array}{l}\text { - Revisão sobre o trabalho com lixo a partir dos seguintes temas: trabalho informal e } \\
\text { saúde coletiva, variabilidades inerentes, discussão da complexidade. }\end{array}$ \\
\hline Análise da demanda & $\begin{array}{l}\text { - Visita exploratória e interação com a secretaria e direção da cooperativa objetivando } \\
\text { ter uma caracterização geral da gestão da cooperativa e indicação de nomes de } \\
\text { trabalhadores para compor o quadro de entrevistados; } \\
\text { - Levantamento do histórico da cooperativa por meio de conversas com os cooperados } \\
\text { e referencial teórico, caracterização da população a partir da interação com os } \\
\text { trabalhadores e caracterização do processo de triagem com a análise de documentos e } \\
\text { observaçães diretas; } \\
\text { - Conformação do recorte de análise para a triagem de materiais recicláveis a partir do } \\
\text { referencial teórico e dos resultados da análise da demanda. }\end{array}$ \\
\hline Análise da tarefa & $\begin{array}{l}\text { - Estudo do processo de triagem na esteira com a divisão da análise em três partes. } \\
\text { Registro e análise da tarefa por meio de observações indiretas (fotografias e filmagens) } \\
\text { e entrevistas simultâneas; } \\
\text { - Análise do trabalho prescrito x real, comparação entre o trabalho previsto pela } \\
\text { cooperativa e o efetivamente realizado; } \\
\text { - Análise do ambiente físico, no qual o trabalho é executado. }\end{array}$ \\
\hline Análise da Atividade & $\begin{array}{l}\text { - Elaboração do roteiro das entrevistas a partir das variabilidades identificadas na } \\
\text { literatura e dos resultados da análise da tarefa (percepção de desconfortos durante o } \\
\text { trabalho, riscos no trabalho, busca por resultados/aceleração do trabalho, relação entre } \\
\text { cooperados e com a direção, entre outros); } \\
\text { - Aplicação das entrevistas semiestruturadas e questionário de distribuição } \\
\text { das dores }{ }^{32,36,37} \text { para } 14 \text { cooperados do setor de triagem, (o setor conta com } \\
\text { aproximadamente } 23 \text { pessoas, a maioria mulheres, com ensino fundamental } \\
\text { incompleto e em média } 50 \text { anos de idade); } \\
\text { - Análise das entrevistas sistematizando a resposta e compilando o discurso coletivo. }\end{array}$ \\
\hline Diagnóstico & $\begin{array}{l}\text { - Elaboração do diagnóstico a partir dos resultados das etapas anteriores, confrontando } \\
\text { o referencial teórico sobre o trabalho com lixo, o contexto da cooperativa enfocada, a } \\
\text { visão da cooperativa sobre a tarefa e a percepção dos trabalhadores. }\end{array}$ \\
\hline
\end{tabular}

Fonte: autor

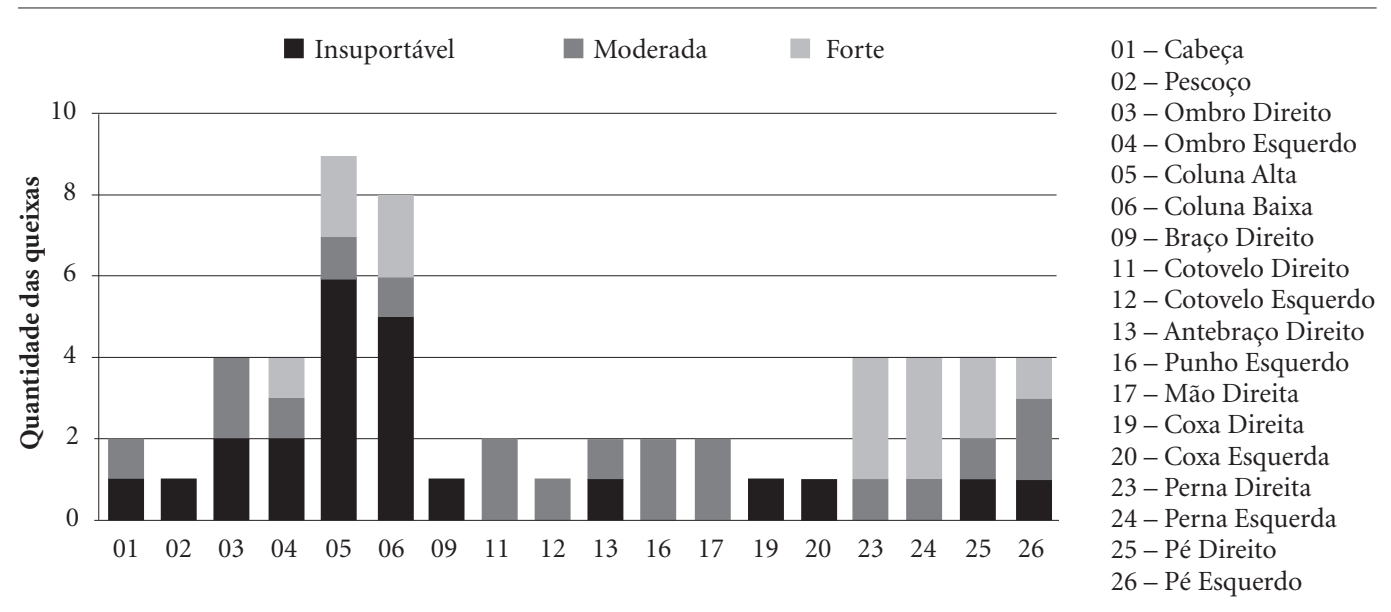

Gráfico 1. Distribuição das queixas de dores: quantidade e intensidade. 
Os relatos evidenciaram que a condição do trabalho era um fator determinante para continuar ou não na cooperativa, inclusive os discursos mostraram que muitos só continuavam na cooperativa porque não conseguiam um emprego formal.

Moisés $^{38}$, concluiu que a alta rotatividade inerente a estas organizações está ligada à precariedade e fragilidade do trabalho. A autora destaca, entre outros, o contato com o lixo e a baixa remuneração como razões para a não permanência na cooperativa. O discurso de uma das cooperadas no estudo de caso reflete a condição negativa do contato com o lixo, "quando eu entrei aqui eu disse: a minha cabeça está rodando, o estomago está embrulhando, eu não vou me acostumar a isso aqui não".

A capacidade de triagem da cooperativa é de vinte toneladas por dia, mas atualmente gira em torno de doze toneladas por falta de mão de obra. A remuneração dos cooperados fica em torno de oitocentos reais por mês, pagos em quinzenas. A baixa remuneração (e consequentemente a falta de força de trabalho), juntamente com os fatores inerentes ao contato com o lixo, também vai influenciar na questão da alta rotatividade.

\section{Aspectos organizacionais e produtivos}

As eleições para diretoria na Cooperfran ocorrem de três em três anos. Destaca-se o conflito de verbalizações sobre as reuniões semanais, a diretora afirma que as reuniões com os cooperados para a tomada de decisões sobre a cooperativa acontecem toda semana e todos podem participar e dar a sua opinião, em contrapartida, os relatos de alguns cooperados indicavam que as reuniões haviam parado, "quando tem reunião eu participo, mas as reuniões pararam”. Porém a maioria respondeu que participa das reuniões, que suas opiniões são respeitadas e não se sentem coagidas para explicitar suas ideias. A ocorrência desses conflitos de opiniões podem expressar outra condição, destacada também por Moisés ${ }^{38}$, a oportunidade de poder votar ou explicitar sua opinião, isoladamente não garante uma situação democrática. Moisés ${ }^{38}$ afirma que talvez por timidez, por temer o confronto ou mesmo por não ter capacidade de entender todas as questões ali discutidas, os cooperados podem abster-se de participar dos processos decisórios em todos os cenários, sejam eles de reuniões periódicas ou de discussões diárias sobre a gestão da cooperativa.

Assim como na literatura foram identificados diversos riscos inerentes ao trabalho com reciclá- veis, destaca-se o risco de cortes com materiais perfuro cortantes, contato com materiais hospitalares e presença de animais peçonhentos. A cooperativa disponibiliza somente as luvas como equipamentos de proteção individual (EPI), mas alguns cooperados não as utilizam e não se preocupam com os riscos, apesar de todos os entrevistados saberem daqueles associados à triagem de materiais recicláveis. Esta constatação corrobora com a pesquisa de Araújo ${ }^{39}$ que verificou que alguns trabalhadores tem a percepção dos riscos, tem à sua disposição alguma proteção, mesmo que mínima, mas não faz uso. $\mathrm{O}$ autor conclui que a falta de uso deve-se à estratégia de defesa que os trabalhadores adotam, que tende naturalizar, minimizar e negar o risco (o que acaba por intensifica-lo ainda mais).

O processo de produção da Cooperfran é dividido da seguinte forma: o material chega da coleta seletiva e é depositado no pátio, este é parcialmente coberto e tem um "buraco"; posteriormente o material vai para a triagem, as saídas deste processo são os materiais separados e os rejeitos; o material triado é armazenado para depois ser prensado e encaminhado para o estoque; e por fim são comercializados. Os rejeitos são deixados em uma área do pátio para que uma empresa terceirizada da prefeitura o encaminhe para o aterro.

Muitas vezes acumula-se uma grande quantidade de materiais recicláveis a ser triado, e segundo discurso dos cooperados essa é a quantidade de materiais que acumula durante o final de semana; um deles durante a entrevista ainda expõe: "segunda feira é o dia mais ruim de trabalhar, o dia que você mais trabalha".

A triagem pode ser dividida em três níveis, conforme sintetizado na Figura 2.

Os caminhões da coleta seletiva despejam o material no "buraco", o guincho, operado por um dos cooperados, transporta o material até o shute, uma caçamba vazada que faz interface com a esteira (nível I). Na esteira, o material é separado pelos cooperados (nível II). Durante a separação na esteira, os cooperados colocam os materiais separados em funis que desembocam nos bags (nível III), os rejeitos caem da esteira e são empurrados para uma área separada do processo (Figura 2).

Ressalta-se que a quantidade de materiais depositados no "buraco" esperando para serem triados é um fator que altera o modo operatório dos cooperados ao longo da esteira. Conforme observações e relatos dos cooperados, quando os materiais que estão na esteira são provenientes 


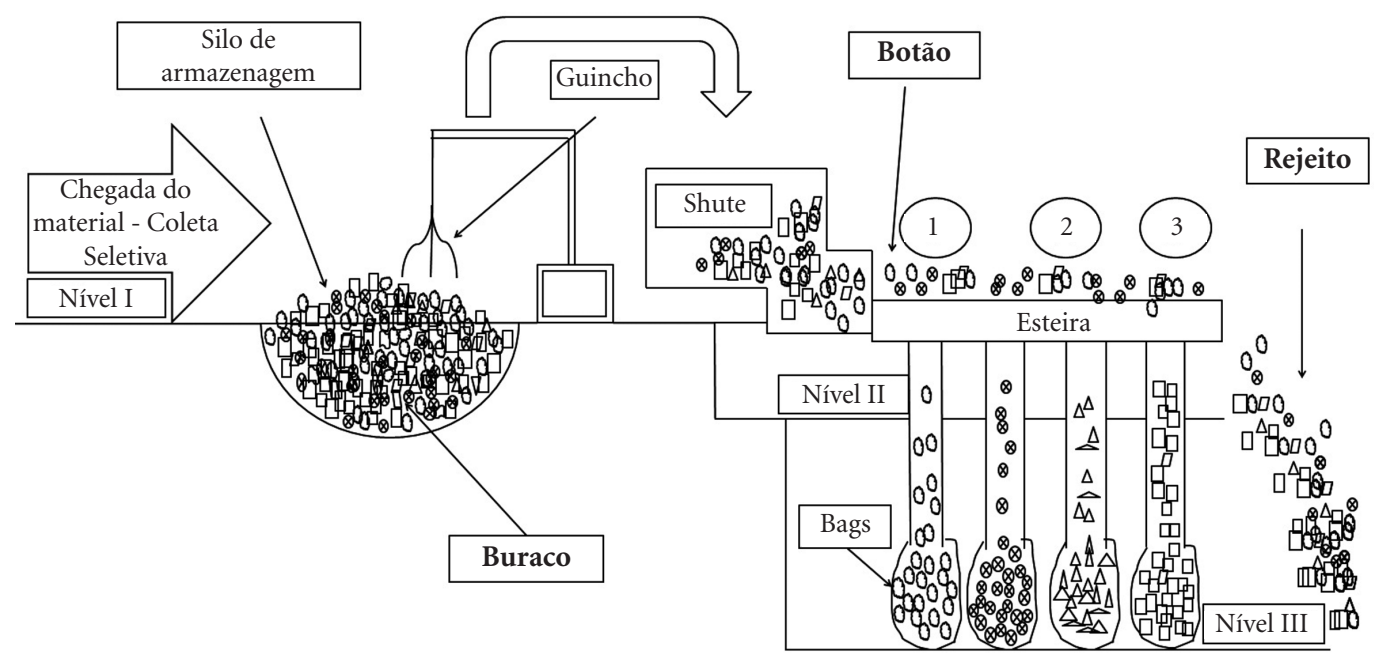

Figura 2. Processo de triagem de materiais recicláveis.

Fonte: autor

das camadas mais fundas do buraco, esses já estão contaminados, sujos, com mau cheiro, os rejeitos já estão em fase de decomposição e há um aumento significativo na quantidade de insetos e ratos que aparecem junto com os materiais.

\section{A atividade ao longo da esteira}

Ao longo da esteira as cooperadas ficam organizadas em duplas, uma em cada lado. Cada uma é responsável por um, dois ou três tipos de materiais, as funções variam de acordo com posição da cooperada na esteira. Observaramse diferentes tipos de problemas, como: furos na estrutura que cobre a esteira, possibilitando que haja gotejamento de agua em dias chuvosos, acúmulo de materiais no chão perto da esteira; falta de manutenção da estrutura; escada de acesso para esteira muito íngreme e estreita, fazendo com que o local de triagem seja de difícil acesso, condições também evidenciadas no trabalho de Rutkouski ${ }^{19}$.

No inicio da esteira (1, ver Figura 2), local de interface com a caçamba de alimentação, conhecido pelos cooperados como "botão", as tarefas são direcionadas a facilitar a triagem ao longo do processo, portanto os cooperados desta parte da esteira abrem "sacolinhas", reviram o material reciclável e os distribuem pela esteira. Além de serem responsáveis pela triagem do papelão e outros materiais em que ninguém está triando na esteira como alumínio que aparece relativamente pouco.

No meio da esteira (2, ver Figura 2) ficam as cooperadas que realizam somente a triagem e conforme explicitado acima tem alguns materiais que são de sua responsabilidade, mas que elas sempre acabam triando mais um ou outro. Em uma das verbalizações, uma das cooperadas afirmou que faz a triagem de vidro, bisnaga branca, bisnaga colorida, plástico duro, lata de ferro e latinha, porém somente os três primeiros são realmente responsabilidade dela.

No final da esteira (3, ver Figura 2) ficam duas cooperadas responsáveis por separar em um bag tudo que deveria ser separado, mas que não foi, depois este bag é jogado novamente no início da esteira.

\section{Análise das variabilidades na triagem e sua gestão}

A pesquisa convergiu para a validação das variabilidades apontadas na literatura, além da identificação de outras associadas à triagem. As variabilidades e a forma como os cooperados realizam sua gestão são descritas a seguir:

a) Variabilidade dos tipos de objetos que chegam à esteira: várias verbalizações refletiram essa situação, citando animais mortos, fezes, lixo hos- 
pitalar, animais peçonhentos vivos, lixo orgânico, etc., "aqui vem de tudo"; "passa escorpião, passa cobra"; "mas demora para passar essas coisas perigosas, escorpião faz uns quinze dias que não passa”. Para fazerem a gestão destas situações os cooperados adotam uma estratégia coletiva de sempre que uma identifica uma dessas situações que podem causar nojo, ou trazer riscos, gritam informando para o restante da esteira. Desta forma, avisados da situação os cooperados aumentam atenção e tomam mais cuidado "aquilo ali pode estar infectado, a gente tem que tomar cuidado"; "se não tomar cuidado a gente pode se ferir".

b) Variabilidade da quantidade de materiais na esteira: a quantidade de materiais que são colocados na esteira variam ao longo do dia, pois dependem da eficiência do guincho, se está ficando muito material amontoado no pátio, de alguma "meta" que a diretoria passa para a esteira, "as vezes a diretora grita, acelera por que precisamos de mais tantos bags de pet". Assim, os cooperados devem acelerar sua triagem, aumentar a concentração para identificar os materiais e não se ferir com os diferentes objetos que chegam na esteira.

c) Variabilidade quanto ao estado dos materiais recicláveis: vários fatores interferem no estado em que o material chega na triagem, destaca-se: a sociedade que não separa o "lixo" corretamente, a exposição do material à chuva ou à quantidade de dias que o material está aguardando para ser triado. Estes fatores contribuem para tornar o material fétido e sujo. Percebe-se uma regulação coletiva quanto a esta variabilidade, quando a triagem atinge as camadas mais fundas do silo de armazenagem, o operador do guincho acelera o processo jogando o máximo possível de materiais na caçamba de alimentação da esteira para acabar logo com esse material. Na esteira, muitos dos cooperados, devido ao cheiro forte, aos perigos em relação a animais, realizam uma triagem visual, e retiram somente os materiais superficiais e que não estão sujos além de também não abrirem lixo em busca de seus materiais. Quando confrontados nas entrevistas em relação a esta situação e que muitos materiais estavam deixando de ser triados, as verbalizações foram as seguintes "é para passar aquele lixo podre"; "não dá para pegar tudo", "quando está sujo ou molhado não compensa”; "ai vai caindo até o preço”, um dos cooperados afirmou que nestas situações o rendimento cai para menos de quarenta por cento frente a setenta com materiais limpos.

Variabilidade na eficiência dos cooperados: por vários fatores os trabalhadores têm oscilações em sua capacidade de realizar as atividades, como fadiga, ritmo próprio lento ou devido a remuneração ser igualitária, alguns dos cooperados simplesmente diminuem o ritmo quando acham necessário, corroborando com outras pesquisas que identificaram a existência de níveis de empenho e comprometimento diferentes ${ }^{13,16,19}$.

De forma a gerir essa situação, muitos cooperados acabam incorporando à sua atividade a triagem de materiais que não são de sua responsabilidade e que não estão sendo triados pelos seus responsáveis, garantindo que os ganhos não sejam comprometidos por essas oscilações. As verbalizações durantes as entrevistas são claras: "tem muita gente folgada aqui"; "tem aquelas que separam certinho e tem aquelas que não"; "do meu lado a peteca não cai, agora do outro"; "seria bom se tivesse um fiscal de esteira”. É possível observar que a dificuldade em organizar o trabalho interno da cooperativa faz com que os próprios cooperados busquem incorporar maneiras de controlar o trabalho, esta situação possivelmente está associada a deficiências na autogestão. Eid e Chiarello $^{40}$ destacam ainda que em algum momento a cooperativa deverá tomar a decisão de manter-se como uma organização que visa somente à subsistência dos seus sócios ou buscar um posicionamento competitivo frente ao mercado, o que irá solicitar uma postura de gestor do cooperado.

d) Variabilidade nos equipamentos: conforme os relatos o guincho costuma quebrar e assim interromper o abastecimento da caçamba de alimentação da esteira, desta forma, alguns cooperados se mobilizam para abastecer a caçamba e assim não parar o processo de triagem. $\mathrm{Na}$ triagem, caso algum dos cooperados tenham ido ajudar no abastecimento outros assumem as suas tarefas.

Variabilidade no controle do trabalho: devido às deficiências na autogestão da cooperativa, a Diretoria passou a concentrar decisões e muitas vezes os cooperados, assim como em Moisés ${ }^{38}$, passam a trabalhar efetivamente somente quando existe um controle por perto. Esta situação pode ser observada na verbalização a seguir, "eu prefiro quando nossa diretora está no botão, porque ela faz a diferença, ela aumenta o ritmo da esteira". Ressalta-se que para aumentar o ritmo da esteira deve-se aumentar a quantidade de materiais que são colocados, já que a velocidade da esteira é constante.

Variabilidade do tempo: como o ambiente no qual é efetuada a triagem é aberto, com estrutura metálica e somente um teto, sem vedações nas laterais, os trabalhadores estão sujeitos às variações 
do tempo, quando está muito quente o ambiente ajuda, pois tem grande a ventilação natural, no inverno o ambiente é bastante frio, quando chove muito não é possível fazer a triagem e quando chove pouco a triagem continua funcionando, mas os funcionários têm que usar uma capa ou uma blusa para não se molharem. Vale ressaltar que os cooperados preferem esse ambiente aberto do que galpões fechados, já que dessa forma o mau cheiro é amenizado.

Durante as observações constatou-se que o teto está em mal estado de conservação, cheio de buracos, então se começar a chover, alguns pontos da esteira vão ficar molhados pelas goteiras. Ressalta-se que alguns materiais tem seu preço de venda reduzido se estiverem molhados, como por exemplo, o papel e o papelão.

\section{Discussão}

A interface realizada pelas cooperativas entre o consumo da população e a indústria de reciclagem é de suma importância para a manutenção da cadeia de reciclagem e consequentemente para a sociedade. No entanto, esta pesquisa corrobora com a literatura quando mostra que a condição da atividade de triagem ainda é precária e insalubre.

Os problemas associados à falta de equipamentos, estrutura física e organizacional, falta de uso de equipamentos de proteção individual e o próprio contato com o "lixo" convergem para que os cooperados sejam submetidos a sobrecargas físicas e mentais no trabalho. Notou-se a partir das verbalizações a negação como estratégia de defesa frente aos constrangimentos. Assim, destacamos a contradição de um dos discursos: “já me acostumei com as coisas que vem para mim na esteira, pra mim tanto faz, mas no final do ano eu vou sair daqui". Dejours e Abdoucheli ${ }^{41}$ afirmam que os trabalhadores empregam as estratégias de defesa no intuito de diminuir a percepção das imposições da organização do trabalho que podem convergir para algum tipo de sofrimento.

A pesquisa mostrou que os cooperados têm diferentes estratégias e modos operatórios para regular sua atividade e dar conta das variabilidades do sistema, porém estas são colocadas em prática em detrimento da sua saúde, seja na aceleração do trabalho ou no aumento da atenção. Wisner ${ }^{42}$ afirma que o grau de dificuldade inerente à gestão momentânea está associado ao esforço cognitivo do trabalhador para identificar as oscilações das características dos equipamentos e materiais durante a atividade.

Consideramos que o sistema da cooperativa reflete em uma atividade complexa na triagem de materiais recicláveis, entendendo que esta é mediada pelo " $\mathrm{e}$ " 43 , pois os cooperados precisam triar rapidamente "e" com segurança " $e$ " se preocupar com os resultados (autogestão) "e" sem sentir nojo "e" ajudar os outros cooperados "e" sob a pressão da prefeitura para aumentar a eficiência.

Nesse contexto, lembrando o significado do trabalho para o sujeito frente à sociedade, concluímos que os cooperados também operam sob uma profunda exclusão social e falta de reconhecimento de sua atividade.

Desta forma, este trabalho buscou evidenciar a condição na qual é realizada a triagem de materiais recicláveis e qual o custo humano associado, principalmente a falta de separação dos materiais recicláveis na origem (residências, indústrias, etc.). Assim, esta pesquisa corrobora com Sisinno e Oliveira $^{7}$ de que a gestão dos resíduos sólidos deve ser tratada como uma questão de saúde pública.

\section{Colaboradores}

RLR Souza trabalhou na coleta de dados, elaboração do instrumento de pesquisa e redação do artigo. ARM Fontes trabalhou na elaboração do instrumento de pesquisa e revisão final. S Salomão trabalhou na revisão final do artigo. 


\section{Referências}

1. Tersac G, Maggi B. O trabalho e a Abordagem ergonômica. In: Daniellou F, organizador. A ergonomia em busca de seus príncipios: debates epistemológicos. $1^{\text {a }}$ ed. São Paulo: Edgard Blücher; 2004. p. 79-104.

2. Castell R. A metamorfose da questão social: uma crônica do salário. Petrópolis: Vozes; 1998.

3. Gomez CM, Thedim-Costa SMF. Precarização do trabalho e desproteção social : desafios para a saúde coletiva. Cien Saude Colet 1999; 4(1):411-421.

4. Costa CM. Reciclagem e cidadania: a trajetória de vida dos catadores de material reciclável da comunidade Reciclo [dissertação]. Brasilia: Universidade de Brasília; 2008.

5. Poulsen OM, Breum NO, Ebbehøj N, Hansen a M, Ivens UI, van Lelieveld D, Malmros P, Matthiasen L, Nielsen BH, Nielsen EM, Schibyea B, Skova T, Stenbaeka EI, Wilkinsa KC. Collection of domestic waste. Review of occupational health problems and their possible causes. Sci Total Environ 1995; 170(1-2):1-19.

6. Cointreau S. Occupational and Environmental health issues of solid waste management: special Emphasis on Middle-and Lower-Income Countries. Washington: The World Bank; 2005

7. Sisinno CLS, Oliveira RM. Resíduos sólidos, ambiente e saúde. In: Sisinno CLS, Oliveira RM, organizadores. Rio de Janeiro: Fiocruz; 2002.

8. Freitas CMD. Problemas ambientais, saúde coletiva e ciências sociais. Cien Saude Colet 2003; 8(1):137-150.

9. Abrahão JI. Reestruturação Produtiva e Variabilidade do Trabalho: Uma Abordagem da Ergonomia. Psicol Teor e Pesqui 2000; 16(1):49-54.

10. Guérin F, Laville A, Daniellou F, Duraffourg J, Kerguelen A. Compreender o trabalho para tranformá-lo: a prática da ergonomia. $1^{\mathrm{a}}$ ed. São Paulo: Blucher; 2001.

11. Gutberlet J, Baeder AM, Pontuschka NN, Felipone SMN, Dos Santos TLF. Participatory research revealing the work and occupational health hazards of cooperative recyclers in Brazil. Int J Environ Res Public Health 2013; 10(10):4607-4627.

12. Gutberlet J, Baeder AM. Informal Recycling and occupational health in Santo André, Brazil. Int J Environ Health Res 2008; 18(1):1-15.

13. Cockell FF, Carvalho AMC, Camarotto JA, Bento PE. A Triagem de Lixo Reciclável : Análise Ergonômica da Atividade. Rev Bras Saúde Ocup 2004; 29(110):17-26.

14. Gómes-Correa JA, Agudelo-Suárez AA, Ronda-Pérez E. Condiciones Sociales y de Salud de los recicladores de Medellín. Rvista Salud Pública 2008; 10(5):706-715.

15. Dall'Agnol CM, Fernandes FS. Saúde e autocuidado entre catadores de lixo: vivências no trabalho em uma cooperativa de lixo reciclável. Rev Lat Am Enferm 2007; 15(Especial):729-735.

16. Oliveira F. Processo de Trabalho e Produção de Vínculos Sociais: Eficiência e Solidariedade na Triagem de Materiais Recicláveis [dissertação]. Belo Horizonte: Universidade Federal de Minas Gerais; 2010.
17. Lazzari MA, Reis CB. Os coletores de lixo urbano no município de Dourados ( MS ) e sua percepção sobre os riscos biológicos em seu processo de trabalho. Cien Saude Colet 2011; 16(8):3437-3442.

18. Binion E, Gutberlet J. The effects of handling solid waste on the wellbeing of informal and organized recyclers: a review of the literature. Int J Occup Environ Health 2012; 18(1):43-52.

19. Rutkowski JE. Sustentabilidade de empreendimentos econômicos solidários: uma abordagem na Engenharia de Produção [tese]. Rio de Janeiro: Universidade Federal do Rio de Janeiro; 2008.

20. Vidal MC. Análise ergonômica do trabalho. In: Másculo FS, Vidal MC, organizadores. Ergonomia: trabalho adequado e eficiente. Rio de Janeiro: Elsevier; 2011. p. 245-283.

21. Silva Junior J. Gestão, fato associativo e economia solidária: a experiência da ASMOCONP/Banco de Palmas. [dissertação]. Salvador: Universidade Federal da Bahia; 2004.

22. Carmo MS, Oliveira JAP. The Semantics of Garbage and the organization of the recyclers: Implementation challenges for establishing recycling cooperatives in the city of Rio de Janeiro, Brazil. Resour Conserv Recycl 2010; 54(12):1261-1268.

23. Vasconcelos RC, Francisco PA, Camarotto JA, Abrey ACMDS, Coutinho Filho AOS. Aspectos de complexidade do trabalho de coletores de lixo domiciliar : a gestão da variabilidade do trabalho na rua. $G \& P 2008$; 15(2):407-419.

24. Ramussen J, Lind M. Coping with complexity. Risø-M $1981 ; 1-28$

25. Leplat J. Aspectos da complexidade em ergonomia. In: Daniellou F, organizador. A ergonomia em busca de seus princípios: debates epistemológicos. São Paulo: Edgar Blütcher; 2004. p. 57-78.

26. Bryman A. Research Methods and Organization Studies. Routledge; 1989.

27. Cervo A, Bervian PA, Silva R. Metodologia Científica. São Paulo: Pearson Prentice Hall; 2007.

28. Miguel PAC. Metodologia de pesquisa em Engenharia de Produção. Rio de Janeiro: Elsevier; 2010.

29. Yin RK. Estudo de Caso: planejamento e métodos. $4^{\mathrm{a}} \mathrm{ed}$. Porto alegre: Bookman; 2010.

30. Lima FPA, Varella CVS, Oliveira FG, Parreiras G, Rutkowski J. Tecnologias Sociais da Reciclagem : Efetivando Políticas de Coleta Seletiva com Catadores. Gerais Rev Interstucional Psicol 2011; 4(2):131-146.

31. Brasil. Portaria MTPS/GM n ${ }^{\circ} 3751$, de 23 de novembro de 1990. Ltr.54-12/1474-NR17 - Ergonomia. Diário Oficial da União 1990; 26 nov.

32. Corlett EN, Bishop RP. A technique for assessing postural discomfort. Ergonomics. 1976; 19(2):175-182.

33. Porto MFS, Juncá DCM, Gonçalves RS, Filhote MIF. Lixo, trabalho e saúde: um estudo de caso com catadores em um aterro metropolitano no Rio de Janeiro, Brazil. Cad Saude Publica 2004; 20(6):1503-1514. 
34. Santos I. Estudo dos riscos de acidentes de trabalho em coletores de lixo. In: IV Fórum Ambiental da Alta Paulista. Tupã; 2008.

35. Sousa CM, Mendes AM. Viver do lixo ou no lixo? A relação entre saúde e trabalho na ocupação de catadores de material reciclável cooperativos no Distrito $\mathrm{Fe}-$ deral - Estudo Exploratório. Psicol Organ e Trab 2006; 6(2):13-42.

36. Rodrigues DS, Menegon FA, Silvério M, Fontes ARM, Menegon NL. A percepção dos operadores sobre a sua condição de trabalho: comparando o antes e o depois da intervenção ergonômica em uma refinaria de petróleo. In: Anais XII Congresso Brasileiro de Ergonomia. Porto Seguro; 2008.

37. Souza TO, Menegon NL. Estratégia de avaliação de ferramentas manuais focada na percepção dos trabalhadores. In: Anais XII Congresso Brasileiro de Ergonomia. Recife, PE; 2002. p. 5.

38. Moisés PM. O trabalho na economia solidária: estudo de caso sobre a rotatividade em uma associação de reciclagem [dissertação]. Belo Horizonte: Universidade Federal de Minas Gerais; 2009.

39. Araújo JA. Percepções e atitudes diante dos riscos ambientais à Saúde de ctadores de materiais recicláveis da comunidade de São José do Coque, Recife/PE [dissertação]. Recife: Fundação Oswaldo Cruz; 2009.

40. Eid F, Chiarello CL. Organização do trabalho e processo decisório em cooperativas populares e tradicionais : estudo de casos em duas cooperativas paranaenses. Rev Econ 2009; 35(2):61-81.

41. Dejours C, Abdoucheli E. Itinerário teórico em psicopatologia do trabalho. In: Dejours C, organizador. Psicodinâmica do trabalho. São Paulo: Atlas; 1994. p. 119-143.

42. Wisner A. A inteligência no trabalho: textos selecionados de Ergonomia. São Paulo: Fundacentro; 1994.

43. Hubalt F. Do que a ergonomia pode fazer a análise? In: Daniellou F, organizador. A ergonomia em busca de seus princípios: debates epistemológicos. São Paulo: Edgard Blütcher; 2011. p. 105-140.

Artigo apresentado em 07/07/2014

Aprovado em 11/07/2014

Versão final apresentada em 12/07/2014 